\title{
Role of polyphenolic acetates and calreticulin induced hyperacetylation via epigenetic modulation on apoptosis in ehrlich ascites tumour mice model
}

\author{
Vishwajeet Rohil', Mujeeb ur Rahman², Neetu Beetan', Anju Sharma ${ }^{1,3}$, Karuna Sharma ${ }^{1,4}$, Ajit Kumar ${ }^{5}$ \\ ${ }^{1}$ Department of Biochemistry, Clinical Biochemistry Laboratory, Vallabhbhai Patel Chest Institute, Delhi, India, ${ }^{2}$ Department of Biostatistics, \\ Vallabhbhai Patel Chest Institute, Delhi, India, ${ }^{3}$ Vardhman Mahavir Medical College \& Safdarjung Hospital, New-Delhi, India, ${ }^{4}$ Department of \\ Biochemistry, Lady Harding Medical College, New Delhi, India, ${ }^{5}$ Department of Chemistry, SRM University, RGEC, Sonepat, Haryana, India
}

Aims and Objectives: Role of Polyphenolic acetates (PAs) was studied to explore their ability to impart acetylation of histone protein by the novel mechanism of acetylation in Ehrlich Ascites tumour (EAT) mice model. Effect of Polyphenolic acetates along with Calreticulin (CAL) in combination with HDAC inhibitor Valproic acid (VA) induced hyperacetylation causing modulation of apoptosis were investigated in view of possibility to develop target oriented combination therapy in cancer. Materials and Methods: EAT bearing mice were treated with different PAs, VA and purified, recombinant calreticulin and their combinations by Intra peritoneal route (I.P) which induced transacetylation of histones resulting in apoptosis. After 26 hrs of the above treatment, $2 \mathrm{ml}$ of peritoneal fluid was aspirated from mice of all the above groups. The peritoneal fluid was studied for the amount of acetylated histone proteins by Western blotting using commercially available specific Anti- Acetyl Histone (Ac-Lys) Antibodies and extent of apoptosis in peritoneal cells by Flow-Cytometry and fluorescence microscopy. Results: The number of apoptotic cells were represented by the Median (25th, 75th percentile) clearly illustrates significant increase in the no. of apoptotic cells in both PAs viz. 7,8-Diacetoxy-4Methyl Coumarin (DAMC) and 6-Acetoxy Quinolone (6-AQ) and their combinations with CAL and VA as compared to DMSO control group and the maximum no. of apoptotic cells were observed in Group DAMC + CAL + VA. Increased extent of histone protein acetylation was observed by Western blotting using specific Anti- Acetyl Histone (Ac-Lys) Antibodies. Conclusion: PAs alone and also synergistically with CAL and VA are potential drug candidates for Cancer therapy.

Key words: Polyphenolic acetates, Ehrlich Ascites tumour, Calreticulin, Valproic acid, 7,8-Diacetoxy-4-Methyl Coumarin, 6-Acetoxy Quinolone
Access this article online Website: http://nepjol.info/index.php/AJMS DOI: 10.3126/ajms.v7i2.13438 E-ISSN: 2091-0576 P-ISSN: $2467-9100$

\section{INTRODUCTION}

Cancer is a genetic disease initiated by alterations in genes, such as oncogenes and tumor suppressors that regulate cell proliferation, survival, and other homeostatic functions. In cancer cells, genes are either modified by mutations, which alter the function of the proteins they encode, or through epigenetics i.e. inheritable modifications to chromosomes that alter gene-expression patterns that do not involve alterations in DNA sequence. This can occur via DNA methylation as well as through covalent modifications of histones proteins around which DNA is wound to form chromatin like Acetylation, Methylation, Ribosylation or Phosphorylation. Imbalance of acetylation and deacetylation levels results in development of malignancies. The heritable alterations in chromatin structure by acetylation of histone and non histone proteins or DNA methylation patterns alter the expression of tumor suppressor genes or oncogenes are associated with particular types of cancer. ${ }^{1}$ Acetylation of histones proteins contributes predominantly to this regulation by altering the chromatin structure and protein activity using acetyl-CoA 
as the acetyl group donor molecule by the enzyme Histone acetyl transferases (HAT).

The enzymatic acetylation of proteins is brought about by enzyme transacetylase (TAase). The transacetylase belongs to class transferase group of enzymes that transfer acetyl group from one acetylated molecule to another molecule whether they are physiological compounds macromolecules or xenobiotics. Acetylation of proteins is of two types:

1. Acetyl-CoA dependent which is always enzymatic or

2. Acetyl-CoA independent which further can be either a). Non-enzymatic or b). Enzymatic.

The acetylation of histones is catalyzed by specific acetyltransferase i.e. Histone acetyl transferase (HAT) as mentioned above and is an example of acetyl-CoA dependent enzymatic acetylation.

Acetylation of cyclooxygenase by acetyl salicylate resulting in the inhibition of prostaglandins production ${ }^{2}$ is an example of acetyl-CoA independent acetylation of protein which is non-enzymatic in nature.

The enzymatic acetylation of protein independent of acetyl CoA was unknown until a unique membrane bound enzyme transacetylase in mammalian cells catalyzing the transfer of acetyl group from polyphenolic acetates (PA) to certain proteins such as: NADPH dependent cytochrome P450 reductase, glutathione S-transferase, nitric oxide synthase resulting modulation of their catalytic activity was discovered in our laboratory. ${ }^{3-8}$ This transacetylase is identified as Calreticulin (CAL), a calcium binding protein in endoplasmic reticulum and termed as Calreticulin transacetylase (CRTAase). ${ }^{5,6}$ Calreticulin is a ubiquitous calcium binding eukaryotic multifunctional protein with large number of diverse cellular functions including calcium storage, chaperone function, regulation of nuclear hormone receptor, modulation of complement activity and transacetylation. ${ }^{9-11}$

The molecular mechanisms in cell transformation processes increasingly indicate that cancer is also an epigenetic disease. Imbalance of acetylation and deacetylation levels results in development of malignancies. HAT and HDAC inhibitors are used as drugs in treatment of different types of cancers. ${ }^{12}$ Acetylation of Histones leads to Chromatin Remodeling which makes the genome accessible for Replication and Gene expression. Histone Acetylation leads to Chromatin open conformation (Euchromatin) thereby making DNA sequence is accessible for various transcription factors which activates gene transcription.

Therefore we intended to study polyphenolic acetates (PAs) to see their ability to impart acetylation of histone protein by the novel mechanism of acetylation in Ehrlich Ascites tumour (EAT) mice model. As enzymes have been used for diagnostic purpose mainly but their use in therapeutics was also intended to be explored in cancer treatment, which was a novel concept in chemotherapy. Calreticulin Transacetylase was used along with PAs in the above model as a therapeutic measure for the first time in an effort to explore possibility to develop specific target oriented therapy in cancer. Effect of HDAC inhibitor Valproic acid alone and in combination with Polyphenolic acetates and also Polyphenolic acetates along with Calreticulin induced hyperacetylation causing modulation of apoptosis was also investigated in view of possibility to develop target oriented combination therapy in cancer. Hence transacetylase activity of CRT in tumour cells in mice by analysing extent of acetylation and apoptosis in peritoneal fluid cells in tumour model of mice was planned. As histone proteins are known to be acetylated by HAT (histone acetyl transferase) by Acetyl-CoA dependent enzymatic acetylation mechanism. Hence it was thought interesting to see whether histone proteins can be catalyzed by Calreticulin transacetylase mediated Acetyl-CoA independent mechanism which was a novel concept. The effect of this kind of acetylation of histone proteins using various Polyphenolic acetates and Calreticulin transacetylase on the induction of apoptosis in the animal model was investigated in an effort to explore the role of Polyphenolic acetates and calreticulin as potential candidates intended for their use as target oriented chemotherapeutic and chemopreventive drugs acting by the above mentioned novel mechanism. Various Polyphenolic acetates namely 6-Acetoxy Quinolone (6-AQ) and 7,8-Diacetoxy-4-Methyl Coumarin (DAMC) were investigated by exploring the modulation of apoptosis as a consequence of the hyperacetylation by the novel mechanism in the above model.

\section{MATERIALS AND METHODS}

\section{Study design}

All animal experiments were performed at V.P. Chest Institute following approval of the Institutional Animal Ethics Committee [IAEC]. The study design include total number of 27 mice, which were be divided into 9 groups of 3 mice each.

The mice were injected with $0.1 \mathrm{ml}$ of Ehrlich Ascites tumour cell line (EAT) by I.P route. It is a mammary gland tumour. $0.1 \mathrm{ml}$ of EAT cell line contains $15-20$ million tumour cells. Then after 10 days of injection the cells entered into exponential phase. ${ }^{13}$ Then these EAT generating mice were given different drugs, compounds and purified, recombinant Calreticulin and their combinations by Intra peritoneal route (I.P) which induced transacetylation of histones resulting in apoptosis. After $26 \mathrm{hrs}$ of the above treatment, $2 \mathrm{ml}$ of peritoneal fluid was aspirated from mice of all the above groups. The peritoneal fluid was studied 
for the amount of acetylated histone proteins and extent of apoptosis in peritoneal cells. All the experiments were done in duplicate.

Characterization of recombinant calreticulin transacetylase (CRT)

Immunoblotting of calreticulin transacetylase with anti-calreticulin

For Western blot analysis, EAT cells were lysed with sample buffer containing $150 \mathrm{mM} \mathrm{NaCl}, 100 \mathrm{mM}$ Tris$\mathrm{HCl}, 1 \%$ Triton X-100, 1 mM EDTA, $10 \mu \mathrm{g} / \mathrm{ml}$ aprotinin, $10 \mu \mathrm{g} / \mathrm{ml}$ pepstatin $\mathrm{A}$, and $10 \mu \mathrm{g} / \mathrm{ml}$ leupeptin. The samples were loaded onto bis-acrylamide gels and separated by SDS-PAGE. Separated proteins were transferred to polyvinyldifluoride membranes and incubated with the Anti-Calreticulin primary antibody (which was procured from Biovision) and horseradish peroxidase-conjugated as secondary antibody with protein markers in the first well. Calreticulin band appeared at $46 \mathrm{kDa}$.

Establishment of calreticulin as transacetylase in vitro Inhibition of GST activity as a measure of transacetylase of the calreticulin activity

Calreticulin has been known to inhibit GST and this property has been used to measure the transacetylase activity of the Calreticulin protein thus it is determined by GST inhibition assay. Enzymes of the Glutathione S-transferase (GST) family are composed of many cytosolic, mitochondrial and microsomal (now designated as MAPEG proteins). Glutathione S-transferase family of enzymes are present in eukaryotes and in prokaryotes, where they catalyze a variety of reactions and accept endogenous and xenobiotic substrates. GSTs catalyze the conjugation of reduced glutathione via a sulfhydryl group to electrophilic centers on a wide variety of substrates. This activity detoxifies endogenous compounds such as peroxidised lipids, as well as breakdown of xenobiotics. Most mammalian isoenzymes have affinity for the substrate 1-chloro-2, 4-dinitrobenzene (CDNB) and Spectrophotometric assays utilising this substrate are commonly used to report GST activity.

\section{Glutathione S-transferase (GST) assay}

The method of Habig et $\mathrm{al}^{14}$ was followed for GST assay using GSH and CDNB as the substrates. The assay was carried out in $1.0 \mathrm{ml}$ spectrophotometer cuvette (1 $\mathrm{cm}$ light path). The reaction mixture consisted of $0.25 \mathrm{M}$ phosphate buffer ( $\mathrm{pH}$ 6.5), purified Calreticulin Transacetylase (12.5 $\mu \mathrm{g}$ protein), and $1 \mathrm{mM}$ CDNB and 1 $\mathrm{mM}$ GSH in a total volume of $1.0 \mathrm{ml}$. The contents were mixed and progress of the reaction was followed at $340 \mathrm{~nm}$ using a UV-Vis Spectrophotometer (Shimadzu) with the kinetic software. It was ensured that the reaction should be linear with respect to time of incubation and enzyme concentration. Increase in the percentage inhibition of
GST by Poyphenolic acetate (DAMC) was interpreted as a measure of Transacetylase activity of the Calreticulin protein.

\section{Establishment of tumor model of mice}

Swiss Albino female mice ( 7 - 8 weeks old) were injected with $0.1 \mathrm{ml}$ by I.P route of tumour cell line, Ehrlich Ascites (a mammary gland tumour). $0.1 \mathrm{ml}$ of this tumour cell line contains 15-20 million tumour cells. After 10 days of the injection the cells entered into exponential phase. ${ }^{15-18}$ Then these EAT generating mice were treated with different compounds, purified recombinant calreticulin and their combinations by Intra peritoneal route (I.P).

\section{Treatment of mice}

Swiss Albino female mice (7- 8 weeks old) were divided into nine treatment groups of 3 mice each and various compounds were injected by I.P route, the doses were as following:

DMSO [Control] $0.1 \mathrm{ml}$, Calreticulin (CAL) $20 \mu \mathrm{g} /$ mouse, Valproic acid (VA) $400 \mathrm{mg} / \mathrm{kg}$, 6-Acetoxy Quinolone (6-AQ) $300 \mathrm{mg} / \mathrm{kg}$ dissolved in $0.1 \mathrm{ml} \mathrm{DMSO}$ and 7,8-Diacetoxy-4-Methyl Coumarin (DAMC) $300 \mathrm{mg} / \mathrm{kg}$ dissolved in $0.1 \mathrm{ml}$ DMSO.

Appropriate control groups were taken and all the experiments were done in duplicate.

After 26 hrs of injecting the compounds by IP route, $2 \mathrm{ml}$ of peritoneal fluid was aspirated from mice of all the groups. The peritoneal fluid was studied for the amount of ACETYLATED PROTIENS and extent of APOPTOSIS in peritoneal cells.

\section{Preparation of peritoneal fluid}

Two $\mathrm{ml}$ of peritoneal fluid was aspirated and the cells in the peritoneal fluid were morphologically characterized as EAC by Wright staining and EAC cells with viability $>95 \%$ by Trypan Blue dye exclusion were processed for further experiments. ${ }^{15}$

The peritoneal fluid was centrifuged with $2 \mathrm{ml}$ Normal saline[N.S] at 1500 r.p.m for $10 \mathrm{~min}$. at $10^{\circ} \mathrm{C}$. After centrifugation the supernatant was washed out. The pellets at the bottom of centrifuge were washed with $2-3 \mathrm{ml}$ of N.S and centrifuged again. The final pellet was divided into two parts and studied for the amount of acetylated histone proteins and apoptosis induced by hyperacetylation of Histone by the above treatment.

\section{STUDIES ON APOPTOSIS}

Apoptosis was studied by analyzing the morphological features of cells on microscopy and appearance of 
hypo-diploid (sub G1) population in flow cytometric measurements of DNA content.

\section{Microscopy}

\section{Preparation of smear and staining}

Cell pellet were suspended in $0.2 \mathrm{ml}$ of acetic acid: methanol and a drop of this suspension was placed on a wet chilled slide, spread to form uniform smear. The smear was stained with DNA specific fluorochrome 4',6-diamidino2-phenylindole (DAPI) (Sigma).

DAPI stained slides were examined using fluorescent microscope (NIKON) with UV mode using blue filter. ${ }^{16}$ The number of apoptotic cells were counted per 1000 EAT cells in each treatment group.

Flow cytometric analysis (using BD flow-cytometer) The method of Dwarkanath et al was followed (17).

- Cells were fixed in $85 \%$ chilled ethanol.

- After overnight fixation ethanol was taken out and a wash with 2-3 $\mathrm{ml}$ PBS was given.

- Ribonuclease solution $200 \mu \mathrm{l} / \mathrm{ml}$ with concentration of $200 \mu \mathrm{g} / \mathrm{ml}$ was added.

- It was incubated at $30^{\circ} \mathrm{C}$ for $30 \mathrm{~min}$.

- Again it was washed with 2-3 $\mathrm{ml}$ of PBS and then $15 \mu \mathrm{g} / \mathrm{ml}$ of Propidium Iodide dye added and incubated at $4^{\circ} \mathrm{C}$ of for $30 \mathrm{~min}$.

- These cells were studied by Flow Cytometry for DNA analysis. Analysis of cell cycle phase distribution pattern of nuclear DNA was done to study apoptosis (appearance of sub-G0/G1 population).

\section{DEMONSTRATION OF HISTONE PROTEIN ACETYLATION BY WESTERN BLOTTING}

The prepared peritoneal fluid was taken and cells were lysed using sonication and extent of histone protein acetylation was determined by Western blotting using commercially available specific Anti- Acetyl Histone H4 (Ac-Lys) Antibodies (Santacruz).

\section{Statistical analysis}

The data was presented as the Median $\left[25^{\text {th }}, 75^{\text {th }}\right.$ percentile] and statistically significant differences among groups were assessed by using analysis of variance (ANOVA) followed by Post hoc test. A p value of less than 0.05 was considered statistically significant.

\section{Ethics}

All animal experiments were performed following approval of the Institutional Animal Ethics Committee [AEC].

\section{RESULTS}

The data was presented as Median $\left(25^{\text {th }}, 75^{\text {th }}\right.$ percentile $)$ and statistically significant differences among Groups has been analyzed by One Way Analysis of Variance followed by Post Hoc Multiple Comparison Tests, Bonferroni's Multiple Comparison Test for Apoptotic studies by Flow Cytometry and Dunn's Multiple Comparison Test for Apoptotic studies by Fluorescence Microscopy. A p value of less than 0.05 was considered statistically significant.

A total of 27 mice, 3 in each group were subjected to 9 treatments DMSO being the control group, 6AQ, VA, DAMC, independently as well as in combination with CAL and also in inclusion with CAL along with VA respectively.

The number of apoptotic cells as represented by the Median $\left(25^{\text {th }}, 75^{\text {th }}\right.$ percentile $)$ clearly illustrates the least no. of apoptotic cells is in DMSO which served as control group and the maximum no. of apoptotic cells were observed in Group VI i.e. DAMC+CAL+VA (Table 1). At the same time, there is concurrent and steep increase in apoptotic cells as represented by median in DAMC alone (Group IV) followed by 6AQ alone (Group VII), VA (Group III) \& CAL (Group II) respectively compared to DMSO Control. The enhancement of apoptotic activity was more in combination of CAL with DAMC (Group V) when compared to combination of CAL with 6AQ (Group VIII) indicating DAMC is much effective than $6 \mathrm{AQ}$ which is further proved by maximum increase in apoptotic cells in DAMC+CAL+VA (Group VI) compared to 6AQ+CAL+VA (Group IX). The apoptotic activity was more in nearly all the Groups where CAL was used as a combination with DAMC and 6AQ compared to Group IV \& Group VII consisting of DAMC alone and 6AQ alone respectively. The findings of both Flow Cytometry and Fluorescence Microscopy data almost all correlated with each other emphasizing the accuracy of the results (Figure 1, 2 and 3).

Statistical analyses were performed using one-way analysis of variance (ANOVA). Differences between the means of each group in each assay were tested using using Bonferroni's and Dunn's Multiple Comparisons Tests as mentioned above. If the mean values of at least one group differed from others with $\mathrm{P}<0.05$, they were considered statistically significant (Tables 2 and 3 ).

In accordance with the Flow cytometric data analysis Bonferroni's multiple comparisons test the comparison of Group I(DMSO Control) with all the remaining Groups except with Group II (CAL) yielded highly significant results(P $<0.0001$ ). Likewise, the comparison of Group II (CAL)with all the remaining groups yielded highly significant results 


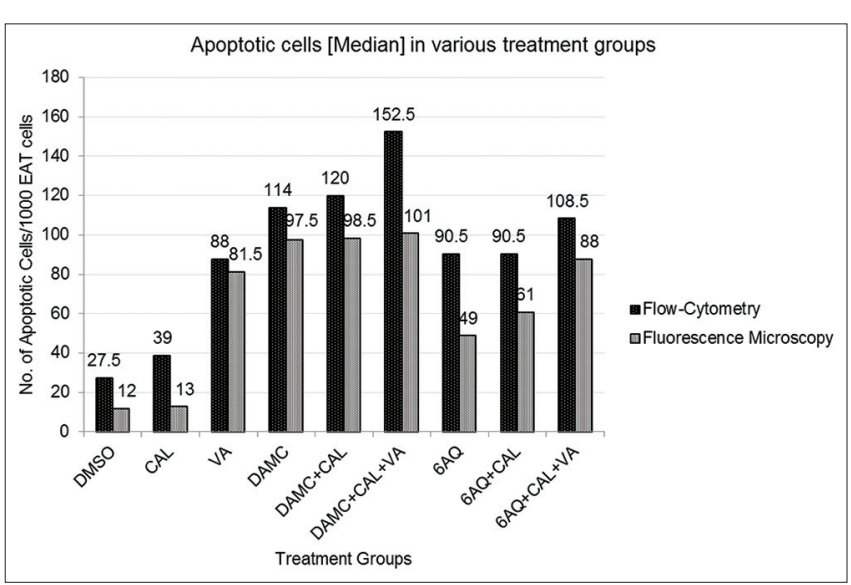

Figure 1: Apoptotic cells [Median] per 1000 EAT Cells in various treatment groups as represented by flow-cytometry and fluorescence microscopy

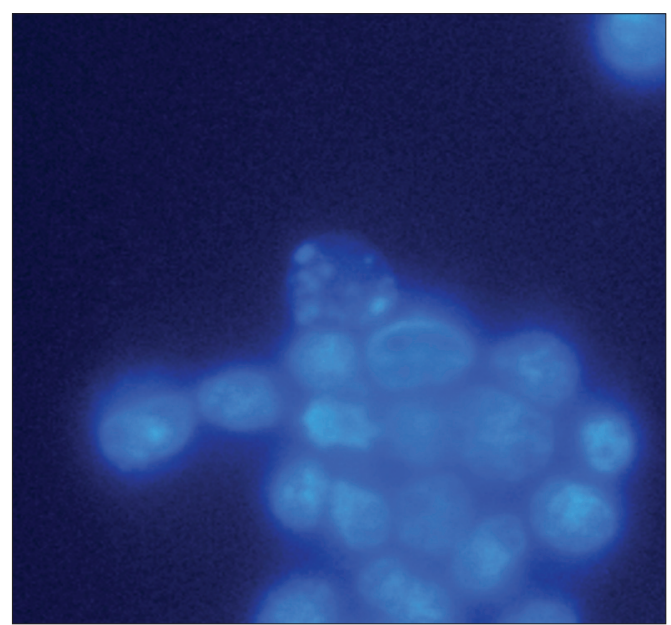

Figure 2: Apoptotic cell lying in the centre of the DAPI stained EAT cell smear as observed by fluorescence microscopy (NIKON)

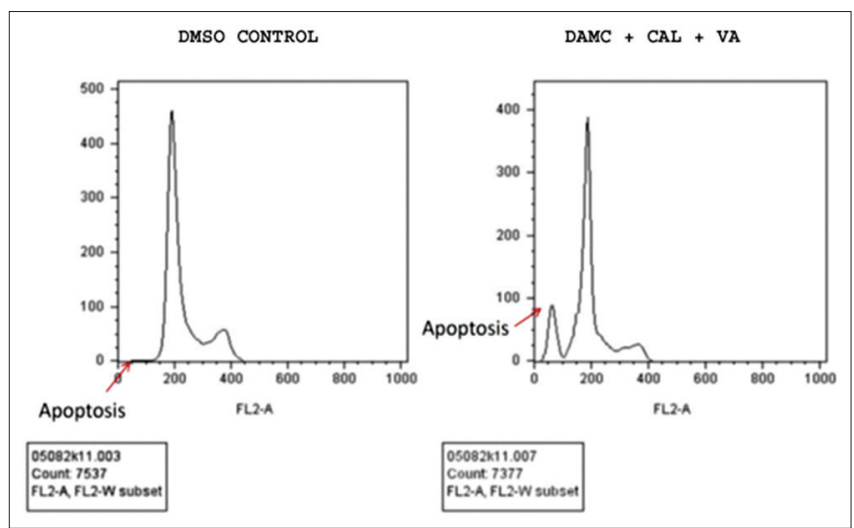

Figure 3: Flow-cytometry analysis representing apoptosis in control and treatment group (BD flow-cytometer)

$(\mathrm{P}<0.0001)$ except with Group I (DMSO Control). The comparison of Group III(VA) with Group V and Group VI i.e. DAMC in combination with CAL and with inclusion of VA respectively yielded significant results. The comparison of Group IV (DAMC alone) with Group VI i.e. DAMC grouped with CAL \& VA yielded significant results. The comparison of Group V (DAMC+CAL) with VI, VII \&VIII i.e. DAMC in combination with CAL and VA, 6AQ alone and in combination with CAL respectively yielded significant results. The comparison of Group VI (DAMC+CAL+VA) with Groups VII, VIII \& IX i.e. 6AQ Alone, in combination with CAL \& with inclusion of VA respectively yielded highly significant results $(\mathrm{P}<0.0001)$ (Table 2$)$.

A total of nine groups were subjected to Dunn's multiple comparisons test to study the statistical significance in the data generated by Apoptotic studies by Fluorescence Microscopy. Each and every treatment group was compared with the rest of the groups including an individual study, Combination with other polyphenolic compounds involved in the study along with CAL (Table 3).

Group I (DMSO Control) when compared with GROUPS IV, V, VI i.e. with DAMC alone, its combination with CAL $\&$ in inclusion with VA respectively along with GROUP IX i.e. $6 A Q+C A L+V A$ yielded significant results. Group II (CAL) when compared with Groups IV, V, VI i.e. DAMC alone, its combination with CAL and with inclusion of VA respectively yielded significant results. Group VI (DAMC +CAL+VA) when compared with Group VII (6AQ alone) yielded significant results.

The rest of the combinations of Group II, III, IV, V, VI, VII, VIII \& IX yielded non-significant results.

The comparison of Group I (DMSO Control) with GROUP VI (DAMC+CAL+VA) and comparison of Group II (CAL) with GROUP VI (DAMC + CAL + VA) yielded highly significant results illustrating high apoptotic activity of DAMC in combination with CAL \&VA.

\section{Demonstration of histone protein acetylation by western blotting}

The treated tumor cells were be lysed using sonication and extent of histone protein acetylation was determined by Western blotting using commercially available specific Anti- Acetyl Histone (Ac-Lys) Antibodies. Acetyl-Histone $\mathrm{H} 4 \mathrm{Ab}$ (Santacruz) was used to assay acetylated histone H4 proteins, acetylated at specific lysine residues (Figure 4). Increased extent of histone protein acetylation was observed by both PAs and VA.

\section{DISCUSSION}

Compared to Control, the no. of apoptotic cells by pretreatment with DAMC alone by was found to be much higher by both the methods compared to 6AQ as obvious from Table 1. Though in One Way Analysis of 


\begin{tabular}{|c|c|c|c|c|}
\hline \multirow[t]{2}{*}{ S. No. } & \multirow{2}{*}{$\begin{array}{l}\text { Treatment } \\
\text { group }\end{array}$} & \multicolumn{3}{|c|}{ Median $\left(25^{\text {th }}, 75^{\text {th }}\right.$ percentile $)$} \\
\hline & & $\begin{array}{l}\text { No. of apoptotic cells } / 100 \\
\text { EAT cells by flow-cytometry }\end{array}$ & $\begin{array}{l}\text { No. of apoptotic cells } / 1000 \\
\text { EAT cells by flow-cytometry }\end{array}$ & $\begin{array}{l}\text { No. of apoptotic cells/1000 EAT } \\
\text { cells by fluorescence microscopy }\end{array}$ \\
\hline $\mathrm{I}$ & DMSO control & $2.75(2.5,3.13)$ & $27.5(25,31.3)$ & $12.00(11,13.5)$ \\
\hline II & Calreticulin (CAL) & $3.9(3.03,4.48)$ & $39(30.3,44.8)$ & $13.00(11.25,16.25)$ \\
\hline III & Valproic acid (VA) & $8.8(8.3,9.6)$ & $88(83,96)$ & $81.50(76,88.5)$ \\
\hline IV & DAMC alone & $11.4(10.13,13)$ & $114(101.3,130)$ & $97.50(89.25,103.5)$ \\
\hline V & $\mathrm{DAMC}+\mathrm{CAL}$ & $12(10.48,13.98)$ & $120(104.8,139.8)$ & $98.50(94.25,101.8)$ \\
\hline VI & $\mathrm{DAMC}+\mathrm{CAL}+\mathrm{VA}$ & $15.25(14.45,15.73)$ & $152.5(144.5,157.3)$ & $101.0(98.75,105.3)$ \\
\hline VII & $6 \mathrm{AQ}$ alone & $9.05(8.68,9.7)$ & $90.5(86.8,97)$ & $49.00(41.5,55.5)$ \\
\hline VIII & $6 \mathrm{AQ}+\mathrm{CAL}$ & $9.05(7.7,10.18)$ & $90.5(77,101.8)$ & $61.00(55.5,66.5)$ \\
\hline IX & $6 A Q+C A L+V A$ & $10.85(9.45,11.98)$ & $108.5(94.5,119.8)$ & $88.00(77,92)$ \\
\hline
\end{tabular}

\begin{tabular}{|c|c|c|}
\hline S. No & Bonferroni's multiple comparisons test & Significance level \\
\hline 1 & Group I (DMSO control) vs Group II (calreticulin, CAL) & NS \\
\hline 2 & Group I (DMSO control) vs Group III (valproic acid, VA) & $P<0.0001$ \\
\hline 3 & Group I (DMSO control) vs Group IV (DAMC alone) & $P<0.0001$ \\
\hline 4 & Group I (DMSO control) vs Group V (DAMC+CAL) & $P<0.0001$ \\
\hline 5 & Group I (DMSO control) vs Group VI (DAMC+CAL+VA) & $P<0.0001$ \\
\hline 6 & Group I (DMSO control) vs Group VII (6AQ alone) & $P<0.0001$ \\
\hline 7 & Group I (DMSO control) vs Group VIII (6AQ+CAL) & $\mathrm{P}<0.0001$ \\
\hline 8 & Group I (DMSO control) vs Group IX (6AQ+CAL+VA) & $P<0.0001$ \\
\hline 9 & Group II (CAL) vs Group III (VA) & $P<0.0001$ \\
\hline 10 & Group II (CAL) vs Group IV (DAMC alone) & $P<0.0001$ \\
\hline 11 & Group II (CAL) vs Group V (DAMC+CAL) & $P<0.0001$ \\
\hline 12 & Group II (CAL) vs Group VI (DAMC+CAL+VA) & $P<0.0001$ \\
\hline 13 & Group II (CAL) vs Group VII (6AQ alone) & $P<0.0001$ \\
\hline 14 & Group II (CAL) vs Group VIII (6AQ+CAL) & $P<0.0001$ \\
\hline 15 & Group II (CAL) vs Group IX (6AQ+CAL+VA) & $P<0.0001$ \\
\hline 16 & Group III (VA) vs Group IV (DAMC alone) & NS \\
\hline 17 & Group III (VA) vs Group V (DAMC+CAL) & $P<0.05$ \\
\hline 18 & Group III (VA) vs Group VI (DAMC+CAL+VA) & $P<0.0001$ \\
\hline 19 & Group III (VA) vs Group VII (6AQ alone) & NS \\
\hline 20 & Group III (VA) vs Group VIII (6AQ+CAL) & NS \\
\hline 21 & Group III (VA) vs Group IX (6AQ+CAL+VA) & NS \\
\hline 22 & Group IV (DAMC alone) vs Group V (DAMC+CAL) & NS \\
\hline 23 & Group IV (DAMC alone) vs Group VI (DAMC+CAL+VA) & $P<0.001$ \\
\hline 24 & Group IV (DAMC alone) vs Group VII (6AQ alone) & NS \\
\hline 25 & Group IV (DAMC alone) vs Group VIII (6AQ+CAL) & NS \\
\hline 26 & Group IV (DAMC alone) vs Group IX (6AQ+CAL+VA) & NS \\
\hline 27 & Group V (DAMC+CAL) vs Group VI (DAMC+CAL+VÁ) & $P<0.01$ \\
\hline 28 & Group V (DAMC+CAL) vs Group VII (6AQ alone) & $P<0.05$ \\
\hline 29 & Group V (DAMC+CAL) vs Group VIII (6AQ+CAL) & $P<0.05$ \\
\hline 30 & Group V (DAMC+CAL) vs Group IX (6AQ+CAL+VA) & NS \\
\hline 31 & Group VI (DAMC+CAL+VA) vs Group VII (6AQ alone) & $P<0.0001$ \\
\hline 32 & Group VI (DAMC+CAL+VA) vs Group VIII (6AQ+CAL) & $P<0.0001$ \\
\hline 33 & Group VI (DAMC+CAL+VA) vs Group IX $(6 A Q+C A L+V A)$ & $P<0.0001$ \\
\hline 34 & Group VII (6AQ Alone) vs Group VIII (6AQ+CAL) & NS \\
\hline 35 & Group VII (6AQ Alone) vs Group IX (6AQ+CAL+VA) & NS \\
\hline 36 & Group VIII $(6 A Q+C A L)$ vs Group IX (6AQ+CAL+VA) & NS \\
\hline
\end{tabular}

Variance followed by Post Hoc Multiple Comparison Tests, Bonferroni's Multiple Comparison Test for Apoptotic studies by Flow Cytometry and Dunn's Multiple Comparison Test for Apoptotic studies by Fluorescence Microscopy both DAMC as well as 6AQ were showing highly significant apoptosis compared to DMSO(Control) and CAL alone. Pretreatment with 6AQ when compared to VA did not show any significant increase in apoptosis as obvious in Table 2. Though in Table 2 Flow Cytometry analysis of apoptotic data DAMC alone pretreatment was also not significant but DAMC+CAL and DAMC +CAL+VA were significantly higher compared to VA Groups but this trend is not seen in Fluorescence Microscopy which is a subjective finding and obviously much less accurate compared to Flow 


\begin{tabular}{|c|c|c|}
\hline S. No & Dunn's multiple comparisons test & Significance level \\
\hline 1 & Group I (DMSO control) vs. Group II (calreticulin or CAL) & NS \\
\hline 2 & Group I (DMSO control) vs Group III (valproic acid or VA) & NS \\
\hline 3 & Group I (DMSO control) vs Group IV (DAMC alone) & $P<0.001$ \\
\hline 4 & Group I (DMSO control) vs Group V (DAMC+CAL) & $P<0.001$ \\
\hline 5 & Group I (DMSO control) vs Group VI (DAMC+CAL+VA) & $P<0.0001$ \\
\hline 6 & Group I (DMSO control) vs Group VII (6AQ alone) & NS \\
\hline 7 & Group I (DMSO control) vs Group VIII (6AQ+CAL) & NS \\
\hline 8 & Group I (DMSO control) vs Group IX (6AQ+CAL+VA) & $P<0.05$ \\
\hline 9 & Group II (CAL) vs Group III (VA) & NS \\
\hline 10 & Group II (CAL) vs Group IV (DAMC alone) & $P<0.01$ \\
\hline 11 & Group II (CAL) vs Group V (DAMC+CAL) & $P<0.001$ \\
\hline 12 & Group II (CAL) vs Group VI (DAMC+CAL+VA) & $P<0.0001$ \\
\hline 13 & Group II (CAL) vs Group VII (6AQ alone) & NS \\
\hline 14 & Group II (CAL) vs Group VIII (6AQ+CAL) & NS \\
\hline 15 & Group II (CAL) vs Group IX (6AQ+CAL+VA) & NS \\
\hline 16 & Group III (VA) vs Group IV (DAMC alone) & NS \\
\hline 17 & Group III (VA) vs Group V (DAMC+CAL) & NS \\
\hline 18 & Group III (VA) vs Group VI (DAMC+CAL+VA) & NS \\
\hline 19 & Group III (VA) vs Group VII (6AQ alone) & NS \\
\hline 20 & Group III (VA) vs Group VIII (6AQ+CAL) & NS \\
\hline 21 & Group III (VA) vs Group IX (6AQ+CAL+VA) & NS \\
\hline 22 & Group IV (DAMC alone) vs Group V (DAMC+CAL) & NS \\
\hline 23 & Group IV (DAMC alone) vs Group VI (DAMC+CAL+VA) & NS \\
\hline 24 & Group IV (DAMC alone) vs Group VII (6AQ alone) & NS \\
\hline 25 & Group IV (DAMC alone) vs Group VIII (6AQ+CAL) & NS \\
\hline 26 & Group IV (DAMC alone) vs Group IX (6AQ+CAL+VA) & NS \\
\hline 27 & Group V (DAMC+CAL) vs Group VI (DAMC+CAL+VA) & NS \\
\hline 28 & Group V (DAMC+CAL) vs Group VII (6AQ alone) & NS \\
\hline 29 & Group V (DAMC+CAL) vs Group VIII (6AQ+CAL) & NS \\
\hline 30 & Group V (DAMC+CAL) vs Group IX (6AQ+CAL+VA) & NS \\
\hline 31 & Group VI (DAMC+CAL+VA) vs Group VII (6AQ alone) & $P<0.05$ \\
\hline 32 & Group VI (DAMC+CAL+VA) vs Group VIII (6AQ+CAL) & NS \\
\hline 33 & Group VI (DAMC+CAL+VA) vs Group IX (6AQ+CAL+VA) & NS \\
\hline 34 & Group VII (6AQ Alone) vs Group VIII (6AQ+CAL) & NS \\
\hline 35 & Group VII (6AQ Alone) vs Group IX (6AQ+CAL+VA) & NS \\
\hline 36 & Group VIII $(6 A Q+C A L)$ vs Group IX (6AQ+CAL+VA) & NS \\
\hline
\end{tabular}

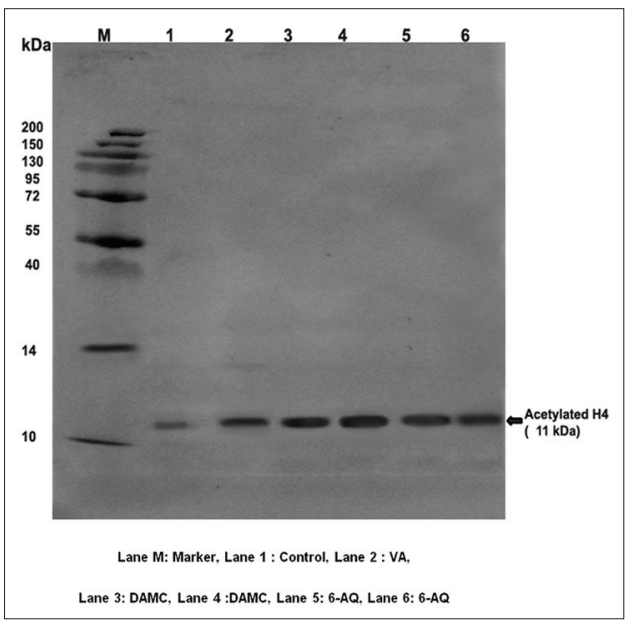

Figure 4: Acetylation of histone H4 in A549 cells after treatment with polyphenolic acetates

Cytometry analysis. In summary, the findings obtained in either of the experimental data (Flow Cytometry \& Fluorescence Microscopy), the major techniques employed for detection of Apoptosis in the present study clearly demonstrated that the increase in Apoptotic cell no. was highly significant when DAMC was used in combination with CAL \& VA. Nevertheless, the remaining treatment groups also showed increased apoptotic activity as represented in the Median $\left(25^{\text {th }}, 75^{\text {th }}\right.$ percentile) when the respective Polyphenolic acetates were grouped with CAL thereby emphasizing the activity of the CAL. Further, these studies demonstrate the apoptotic activity of Polyphenolic actates singly and as well as in combination with CAL which could bring new insight in the direction of therapeutic intervention for cancer. Although there is much more to learn, our current understanding of apoptosis may provide new avenue for cancer therapy. In the coming years, it seems likely that rational strategies to manipulate cell suicide programs by epigenetic modulation will produce new therapies that are less toxic and mutagenic than current treatment regimens. First time the Acetylation of Histone proteins by the Novel method is being demonstrated. We have demonstrated Calreticulin Transacetylase catalyzed 
modification of functional protein Histone with various combinations of Polyphenol acetates and HDAC inhibitors by Western blotting using commercially available Specific Anti Acetyl-Histone H4 Antibodies. Thereby the role of Epigenetic modulation by Acetylation of Histone proteins by the Novel method has been established.We have obtained highly encouraging results by the acetoxy drug (DAMC and 6-AQ): protein transacetylase acetylation system (CRTAase system) mediated acetylation of Histone proteins leading to enhanced apoptosis. These results are enabling us to recommend the potential use of (DAMC and 6-AQ): protein transacetylase acetylation system (CRTAase system) as target oriented anti-cancer drug.

\section{CONCLUSION}

As reported in literature that histone acetylation via HDAC inhibitors leads to increased gene expression, and considering our highly encouraging results we suggest that acetoxy drug (DAMC and 6-AQ): protein transacetylase acetylation system (CRTAase system) mediated hyeracetylation of Histone proteins leads to enhanced apoptosis. Thereby proving them to be developed as a highly potential candidate for target oriented chemotherapeutic and chemopreventive drugs for treating Ehrlich's ascites carcinoma cells which can be extended to treat other types of tumors too for which further research including clinical trials are required.

Hence, Polyphenolic acetates namely DAMC as well as 6AQ in combination with CAL and VA thus proved to be highly apoptotic causing treatment combination in increasing the apoptosis in tumor cells in in vivo model. Thus, these Polyphenolic acetates alone and also synergistically with CAL and VA are potential drug candidates for Cancer therapy. To delineate the exact molecular mechanisms of this effect further studies are required so that these drugs can be used as Cancer treating agents after studying their pharmacokinetics and clinical trials.

\section{ACKNOWLEDGEMENT}

Thanks to Dr. J. S. Adhikari, INMAS for intellectual contribution.

\section{REFERENCES}

1. Hake SB, Xiao A and Allis CD. Linking the epigenetic language of covalent histone modifications to cancer. $\mathrm{Br} \mathrm{J}$ Cancer 2004; 90: 761-769.

2. Vane JR. Inhibition of Prostaglandin synthesis as a mechanism of action for aspirin like drugs. Nature New Biol 1971; 231: 232-234.

3. Raj HG, Parmar VS, Jain SC, Kohli E, Ahmad N, Goel S, et al. Mechanism of biochemical action of substituted 4-methylbenzopyran-2-ones. Part 7: Assay and characterization of7, 8-diacetoxy-4-methylcoumarin: protein transacetylase from rat liver microsomes based on the irreversible inhibition of cytosolic glutathione S-transferase. Bioorg Med Chem 2000; 8: 1707-1712.

4. Raj HG, Kumari R, Seema G, Kumar R, Saluja D, Muralidhar KM, et al. Novel function of calreticulin: characterization of calreticulin as a transacetylase mediating protein acetylation independent of Acetyl CoA using polyphenolic acetates. Pure and Applied Chemistry 2006: 78 (5): 985-992.

5. Seema G, Kumari R, Gupta G, Saluja D, Kumar A, Goel S, et al. Characterization of protein transacetylase from human placenta as a signaling molecule calreticulin using polyphenolic peracetates as the acetyl group donors. Cell biochemistry and biophysics 2007; 47: 53-64.

6. Kohli E, Gaspari M, Raj HG, Parmar VS, Vander Greef J, Gupta G, et al. Establishment of the enzymatic protein acetylation independent of acetyl CoA: Recombinant glutathione S- transferase 3-3 is acetylated by a novel membrane - bound transacetylase using 7,8- diacetoxy-4- methyl coumarin as the acetyl donor. FEBS Lett 2002; 530: 139-142.

7. Kohli E, Gaspari M, Raj HG, Parmar VS, Sharma SK, Vander Greef J, et al. Acetoxy Drug: Protein Transacetylase of buffalo liver- characterization and mass spectrometry of the acetylated protein product. Biochim Biophys Acta 2004; 1698: 55-66.

8. Kumari R, Bansal S, Gupta G, Arora S, Kumar A, Goel G, et al. Calreticulin transacylase: Genesis, mechanism of action and biological applications. Biochimie 2010; 92(9): 1173-1179.

9. Michalak M, Milner RE, Burns $\mathrm{K}$ and Opas M. Calreticulin. Biochem J 1992;285: 681-692.

10. Krause KH and Michalak M. Calreticulin. Cell. 1997; 88: 439-443.

11. Michalak M, Corbett EF, Mesaeli N, Nakamura K and Opas M. Calreticulin: one protein, one gene, and many functions. Biochem J 1999; 344: 281-292.

12. Minucci $S$ and Pelicci PG. Histone deacetylase inhibitors and the promise of epigenetic (and more) treatments for cancer. Nat Rev Cancer 2006; 6:38-51.

13. Belakavadi M, Prabhakar BT and Salimath BP. Butyrate-induced proapoptotic and antiangiogenic pathways in EAT cells require activation of CAD and downregulation of VEGF. Biochemical and Biophysical Research Communications 2005; 335 (4):993-1001.

14. Habig WH, Pabst MJ and Jakoby WB. Glutathione S-transferases: the first enzymatic step in mercapturic acid formation. J Biol Chem 1974; 249: 7130-7139.

15. Bhattacharyya A, Choudhuri T, Pal S, Chattopadhyay S, Datta GK, Sa G, et al. Apoptogenic effects of black tea on Ehrlich's ascites carcinoma cell. Carcinogenesis 2003; 24: 75-80.

16. Varshney R, Gupta S, Dwarakanath BS. Radiosensitization of murine Ehrlich ascites tumor by a combination of 2-deoxy-Dglucose and 6-aminonicotinamide. Technol Cancer Res Treat. 2004;3(6): 659-663.

17. Dwarkanath BS, Zolzer F, Chandana S, Baush T, Adhikari JS, Mullar WU, et al. Heterogeniety in 2-deoxy-D-glucose-induced modifications in energetics and radiation responses of human tumor cell lines. Int J Radiat Oncol Biol Phys 2001; 50:1051-1061.

18. Gupta S, Mathur R, Dwarakanath BS. The glycolytic inhibitor 2-deoxy-D-glucose enhances the efficacy of etoposide in ehrlich ascites tumor-bearing mice. Cancer Biol Ther. 2005;4(1):87-94. 